\title{
The effects of turbulent collision-coalescence on precipitation formation and precipitation-dynamical feedbacks in simulations of stratocumulus and shallow cumulus convection
}

\author{
C. N. Franklin \\ CSIRO Marine and Atmospheric Research, Aspendale, Victoria, Australia
}

Centre for Australian Weather and Climate Research, a partnership between CSIRO and the Australian Bureau of Meteorology, Aspendale, Victoria, Australia

Correspondence to: C. N. Franklin (charmaine.franklin@csiro.au)

Received: 17 December 2013 - Published in Atmos. Chem. Phys. Discuss.: 24 January 2014

Revised: 16 April 2014 - Accepted: 21 May 2014 - Published: 1 July 2014

\begin{abstract}
A double moment warm rain scheme that includes the effects of turbulence on droplet collision rates has been implemented in a large-eddy model to investigate the impact of turbulence effects on clouds and precipitation. Simulations of shallow cumulus and stratocumulus show that different precipitation-dynamical feedbacks occur in these regimes when the effects of turbulence are included in the microphysical processes. In both cases inclusion of turbulent microphysics increases precipitation due to a more rapid conversion of cloud water to rain. In the shallow convection case, the greater water loading in the upper cloud levels reduces the buoyancy production of turbulent kinetic energy and the entrainment. The stratocumulus case on the other hand shows a weak positive precipitation feedback, with enhanced rainwater producing greater evaporation, stronger circulations and more turbulence. Sensitivity studies in which the cloud droplet number was varied show that greater number concentrations suppress the stratocumulus precipitation leading to larger liquid water paths. This positive second indirect aerosol effect shows no sensitivity to whether or not the effects of turbulence on droplet collision rates are included. While the sign of the second indirect effect is negative in the shallow convection case whether the effects of turbulence are considered or not, the magnitude of the effect is doubled when the turbulent microphysics are used. It is found that for these two different cloud regimes turbulence has a larger effect than cloud droplet number and the use of a different bulk microphysics scheme on producing rainfall in shallow cumuli. However, for the stratocumulus case exam-
\end{abstract}

ined here, the effects of turbulence on rainfall are not statistically significant and instead it is the cloud droplet number concentration or the choice of bulk microphysics scheme that has the largest control on the rain water.

\section{Introduction}

Cloud microphysical parameterisations are required in atmospheric models of all scales from large-eddy simulation models through to climate models. Correctly representing microphysical processes in models is challenging yet imperative for quantitative precipitation forecasting and climate studies. To enable greater confidence in climate projections one of the processes that requires a quantitative analysis is the second aerosol indirect effect, which is the effect from enhanced aerosol concentrations in clouds suppressing drizzle and prolonging cloud lifetimes (Albrecht, 1989). To be able to quantify this effect with any real certainty, the cloud microphysical processes must be accurately represented in global climate models (GCMs), in particular the autoconversion process, which describes the collision and coalescence of small droplets to form larger rain drops.

In clouds where the temperature does not reach freezing, it is the process of collision and coalescence that allows drops to grow to a size large enough to fall out of a cloud as rain. Observations of droplet growth tend to show a faster evolution and broader drop size distribution compared to the theoretically calculated drop spectra, where the equations are 
applied to a randomly distributed population of drops whose motion is governed by gravitational forcing (see review by Grabowski and Wang, 2013). Several physical effects have been suggested to play an important role in the reduction of the growth times, including entrainment and mixing of dry air, turbulence and the role of giant cloud condensation nuclei (e.g. Beard and Ochs, 1993). Turbulence increases the collision rate of droplets in at least three ways: by changing the droplet velocities and the spatial distribution of the droplets (e.g. Franklin et al., 2005), and by changing the collision and coalescence efficiencies between droplets. Although the effect of turbulence on cloud droplet collision-coalescence rates is yet to be quantified by observations, modelling studies have shown that turbulence can increase the collision rates of droplets by several times the purely gravitational rate (Franklin et al., 2005, 2007; Wang et al., 2005; Pinsky et al., 2006).

Franklin et al. (2007) performed direct numerical simulations (DNSs) of droplets within turbulent flow fields and developed empirically derived equations that describe the turbulent collision kernel for droplet pairs, where the larger droplet is within the radius range of $10-30 \mu \mathrm{m}$ and the eddy dissipation rate of turbulent kinetic energy (TKE) is between 100 and $1500 \mathrm{~cm}^{2} \mathrm{~s}^{-3}$. The collision kernels from Franklin et al. (2007) were shown to be in good agreement with those of Kunnen et al. (2013), who used a novel technique to simulate the turbulent flow field in their DNS. These turbulent collision kernels were used in solutions of the stochastic collection equation (SCE) by Franklin (2008) to develop empirical double-moment parameterisations of the effect of autoconversion, accretion and self-collection on the rain and cloud water mixing ratios and the rain and cloud drop number concentrations. Parameterisations using both turbulent and non-turbulent collision kernels were developed. The SCE was solved for liquid water contents in the range of $0.01-2 \mathrm{~g} \mathrm{~kg}^{-1}$, cloud droplet number concentrations up to 500 drops $\mathrm{cm}^{-3}$ and relative dispersion coefficients of the initial drop size distribution between 0.25 and 0.4 . The initial drop size distribution was a Gamma function and the separation radius that determined the point at which a cloud droplet becomes a raindrop was $40 \mu \mathrm{m}$. Using the SCE results for such a broad range of drop size distributions gives the resulting parameterisations greater statistical meaning and applicability. The two suites of warm rain parameterisations, turbulent and non-turbulent, allow the investigation of the effect of turbulence on the microphysical processes and the resulting feedbacks in atmospheric models. These effects are explored in this work for stratocumulus and shallow cumulus convection cases. Section 2 describes the model and the two cases to be examined. Section 3 presents the results for the simulated cloud and dynamical structures and Sect. 4 shows the sensitivity of the results to changes in cloud droplet number concentrations. This is followed by a summary of the findings in Sect. 5.

\section{Experiment design}

The double-moment warm rain microphysics parameterisations of Franklin (2008) have been implemented in the University of California Los Angeles Large Eddy Simulation (UCLA-LES) model. The anelastic LES code is described in Stevens et al. (2005) and solves prognostic equations for the three velocity components, the total water mixing ratio, the liquid water potential temperature and the mass and number concentration of rain. Time integration of the momentum equations uses a leapfrog scheme and scalars are advanced using a forward-in-time method. Advection of the velocity components is solved using fourth-order centred differences and scalars are advected using a higher-order upwind scheme with slope limiting using a monotonic centred method. Subgrid fluxes are modelled using the Smagorinsky-Lilly model. The mass of cloud water is defined implicitly due to the dependence of the liquid water potential temperature on the total condensate, and the cloud droplet number concentration is a fixed parameter. The numerical solution of the cloud processes, including droplet sedimentation, is described in Savic-Jovcic and Stevens (2008), except that in this work the separation threshold radius for cloud and rain is taken to be the default values of 40 microns for the schemes of Seifert and Beheng (2001) and Franklin (2008), and 25 microns for Khairoutdinov and Kogan (2000).

In this work the cloud droplet number concentration (CDNC) is constant. Observations of the shallow cumulus case described in Sect. 2.1 show an approximately constant droplet concentration with height (vanZanten et al., 2011). Slawinska et al. (2012) demonstrated the reason behind the observed constant CDNC being due to significant in-cloud activation of cloud condensation nuclei. Using a bin microphysics LES, Wyszogrodzki et al. (2013) showed that while CDNCs were constant with height for the majority of occurrences in their simulations, there is variability in the CDNC fields. Therefore, while the use of a constant CDNC is a good assumption, variations in CDNC will likely affect the development of precipitation and this will not be captured in the simulations presented in this work.

The default bulk microphysics scheme in the UCLALES is that of Seifert and Beheng (2001). In this study the autoconversion and accretion parameterisations of Franklin (2008) are the main subject of investigation. However, results from the default scheme and that of Khairoutdinov and Kogan (2000) are also used to give some indication of the range of results from different microphysics schemes. The turbulent autoconversion equation of Franklin (2008) has been modified to the following form, which gives a better representation of the DNS data at higher cloud water contents:

$$
\begin{aligned}
& \left.\frac{\partial q_{\mathrm{r}}}{\partial t}\right|_{\text {auto }}=2.0026 \times 10^{3} \tan \left(-5.2 \times 10^{-2} R_{\lambda}+15.78\right) \\
& q_{\mathrm{c}}^{97.45\left(-8.4 \times 10^{-1}\right)^{R^{\lambda}}+2.5} \\
& N_{\mathrm{c}}^{1 /\left(-9.0 \times 10^{-1}+1.28 \times 10^{-2} R_{\lambda}-2.3 \times 10^{-4} R_{\lambda}^{2}\right)}
\end{aligned}
$$


where $q_{\mathrm{r}}$ and $q_{\mathrm{c}}$ are the rain and cloud water contents $\left(\mathrm{kg} \mathrm{m}^{-3}\right), N_{\mathrm{c}}$ is the cloud droplet concentration $\left(\mathrm{cm}^{-3}\right)$ and $R_{\lambda}$ is the Taylor microscale Reynolds number of the flow field. This expression will underestimate the effects of turbulence on droplet collision-coalescence due to the use of gravitational collision efficiencies. Limited data are available for the effects of turbulence on collision efficiencies. Currently the DNS data available only provide two data points, for dissipation rates of 100 and $400 \mathrm{~cm}^{2} \mathrm{~s}^{-3}$ (Wang et al., 2008). To include the turbulent collision efficiencies in this work would require them to be extrapolated out to dissipation rates of $1500 \mathrm{~cm}^{2} \mathrm{~s}^{-3}$. The collision kernel results show that the effects of turbulence do not scale linearly with dissipation rate (Franklin et al., 2007) and two data points do not provide enough information to represent this process with any certainty for the high dissipation rates. Therefore, the decision was made not to include the turbulent collision efficiencies until more DNS data become available.

In the implementation of the parameterisations of Franklin (2008) and (1), Eq. (4) of Franklin (2008) has been used to eliminate the dependence on $R_{\lambda}$ and make the dependence solely a function of the dissipation rate of TKE. The parameterisations of Franklin (2008) only consider the effects of turbulence on small collector cloud droplets with radii between 10 and 30 microns. For these small droplets it is the dissipation range turbulence that governs the droplet motion (e.g. Wang and Maxey, 1993) and, therefore, the dissipation rate is the dominant flow property that determines the collision rate, with the Reynolds number effect of significantly less importance. This is illustrated in Fig. 4 of Ayala et al. (2008) who show that $R_{\lambda}$ effects are only apparent for droplets of radius 40 microns and larger, which are larger than the size of droplets considered in Franklin (2008). This result is also described in Wyszogrodzki et al. (2013) who state that small drops with radius less than 30 microns are not affected by the root mean square velocity, which is the $R_{\lambda}$ dependence. This is the reasoning behind the parameterisations of Franklin (2008) and (1) being a function of the dissipation rate only. The DNS simulations used as the basis for this work covered a much wider range of dissipation rates applicable for cloud conditions than other studies, ranging from 100 up to $1500 \mathrm{~cm}^{2} \mathrm{~s}^{-3}$.

As in the approach of Seifert et al. (2010), in the LES implementation of the microphysics scheme $R_{\lambda}$ is calculated from the grid box mean dissipation rate of TKE. Wyszogrodzki et al. (2013) showed that neglecting LES subgrid scale effects on the turbulent enhancement of the gravitational kernel is a reasonable approximation given the current state of knowledge. The autoconversion parameterisation (1) and the implementation described was used by Wang et al. (2013), where this equation and method was shown to produce cloud droplet and rain drop number concentrations and mixing ratios that were in better agreement with observations compared to other autoconversion schemes.

\subsection{Description of the shallow convection case - RICO}

The initial and boundary conditions and large-scale forcings are taken from the Global Energy and Water Experiment (GEWEX) Cloud Systems Study (GCSS) Boundary Layer Cloud Working Group (BLCWG) intercomparison case described by vanZanten et al. (2011). This is a composite case based on observations taken during an undisturbed period of the Rain in Cumulus over the Ocean (RICO) field study (Rauber et al., 2007), which sampled precipitating trade wind cumulus. The domain size of these experiments is $13.2 \mathrm{~km}$ square and $5 \mathrm{~km}$ deep, with grid spacing of $100 \mathrm{~m}$ in the horizontal and $40 \mathrm{~m}$ in the vertical. The time step is variable and is chosen so as to keep the Courant number between 0.65 and 0.85 . The average observed cloud droplet number concentration during RICO was $70 \mathrm{~cm}^{-3}$, and that number has been used for the control simulations. The length of the simulations for this case are $24 \mathrm{~h}$ and the profile statistics are taken as averages over the last $4 \mathrm{~h}$. After the initial spin up, the model produces numerous shallow precipitating convective clouds as shown in Fig. 1a. The clouds typically extend up to $2400 \mathrm{~m}$, have cloud bases at around $600 \mathrm{~m}$ and tend to be $1-2 \mathrm{~km}$ in horizontal extent (Fig. 1b).

\subsection{Description of the stratocumulus case - RF02 of DY- COMS II}

This case is based on the aircraft measurements taken during the second research flight (RF02) of the second Dynamics and Chemistry of Marine Stratocumulus (DYCOMS II) field campaign (vanZanten and Stevens, 2005). The initial conditions and large-scale forcings are taken from the GCSS BLCWG intercomparison study documented by Ackerman et al. (2009). RF02 penetrated nocturnal stratocumulus under a dry inversion consisting of heavy drizzling open cellular convection, as well as lightly drizzling closed cells. The initial conditions are an average over the two cloud populations sampled, except for the cloud droplet number concentration which is the average over the open cells only and set to $55 \mathrm{~cm}^{-3}$. The horizontal domain and grid spacing for this case study are $6.6 \mathrm{~km}$ square and $50 \mathrm{~m}$ respectively, while the vertical domain is $2 \mathrm{~km}$ and the grid spacing varies from $5 \mathrm{~m}$ at the surface and the inversion to $80 \mathrm{~m}$ at the model top. The model is run for $6 \mathrm{~h}$ and the profile statistics are calculated over the final $4 \mathrm{~h}$. Typical liquid and rain water cross sections are shown in Fig. 2. Maximum liquid water contents occur at cloud top and precipitation reaches the surface.

\section{Simulated cloud and dynamical structure}

\subsection{Shallow cumulus convection - RICO}

The turbulent microphysics parameterisations are applied in the regions of the clouds where the dissipation rates of TKE are between 100 and $1500 \mathrm{~cm}^{2} \mathrm{~s}^{-3}$, with the higher 


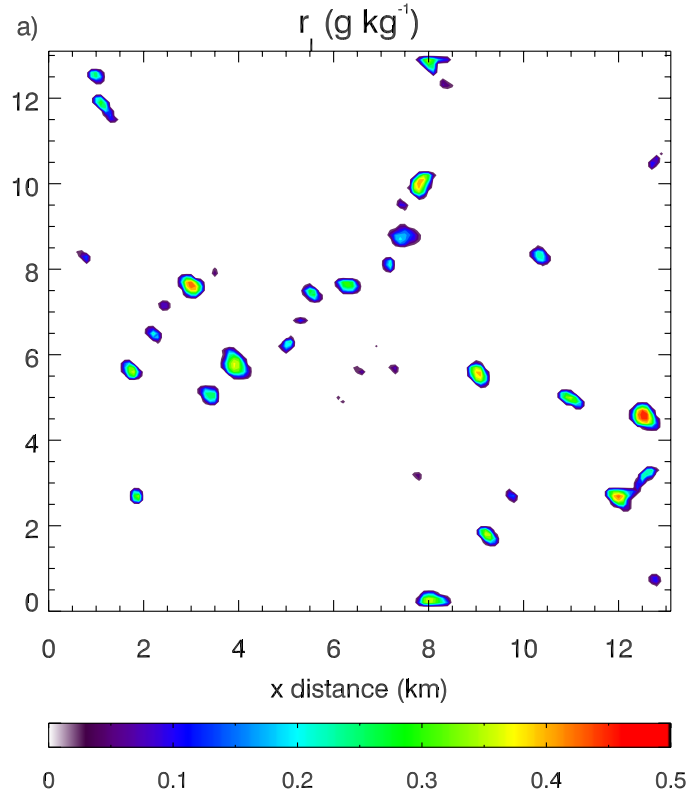

b) $\quad \mathrm{r}\left(\mathrm{g} \mathrm{kg}^{-1}\right)$ \& the dissipation rate $\left(\mathrm{cm}^{2} \mathrm{~s}^{-3}\right)$

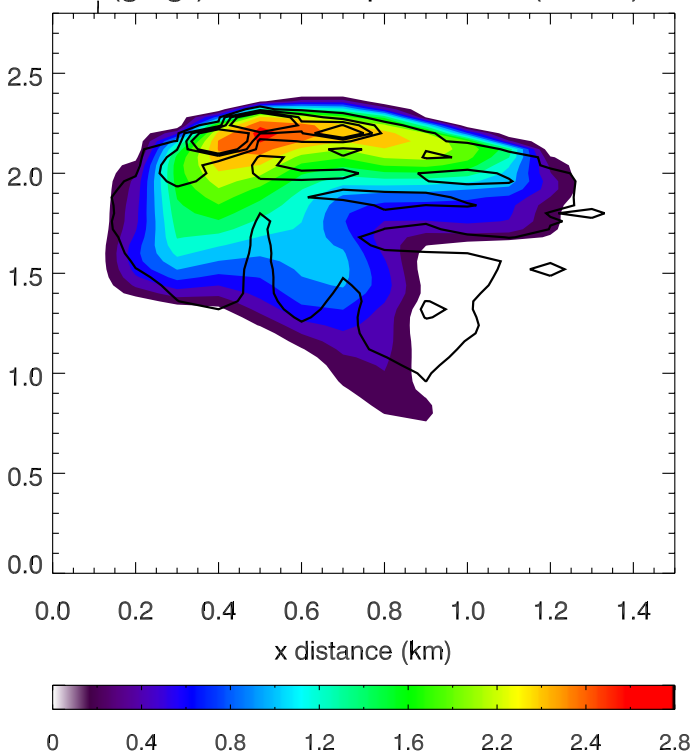

Figure 1. (a) Plan view of RICO liquid water mixing ratio $\left(\mathrm{g} \mathrm{kg}^{-1}\right)$ at $840 \mathrm{~m}$ and (b) cross section through a typical cloud showing liquid water mixing ratio $\left(\mathrm{g} \mathrm{kg}^{-1}\right)$ and contour lines of the dissipation rate of turbulent kinetic energy (contour levels are 100, 500, 1000, $1500 \mathrm{~cm}^{2} \mathrm{~s}^{-3}$ ).

dissipation rates associated with faster conversion rates from cloud to rain water (Franklin, 2008). In the RICO case the range of dissipation rates for which the turbulent microphysics scheme is valid is encountered in extensive regions of the clouds, with the highest dissipation rates occurring near the cloud tops (see Fig. 1b). These increased autoconversion, accretion and self-collection rates increase the rain water mixing ratio of the clouds as compared to the simu-
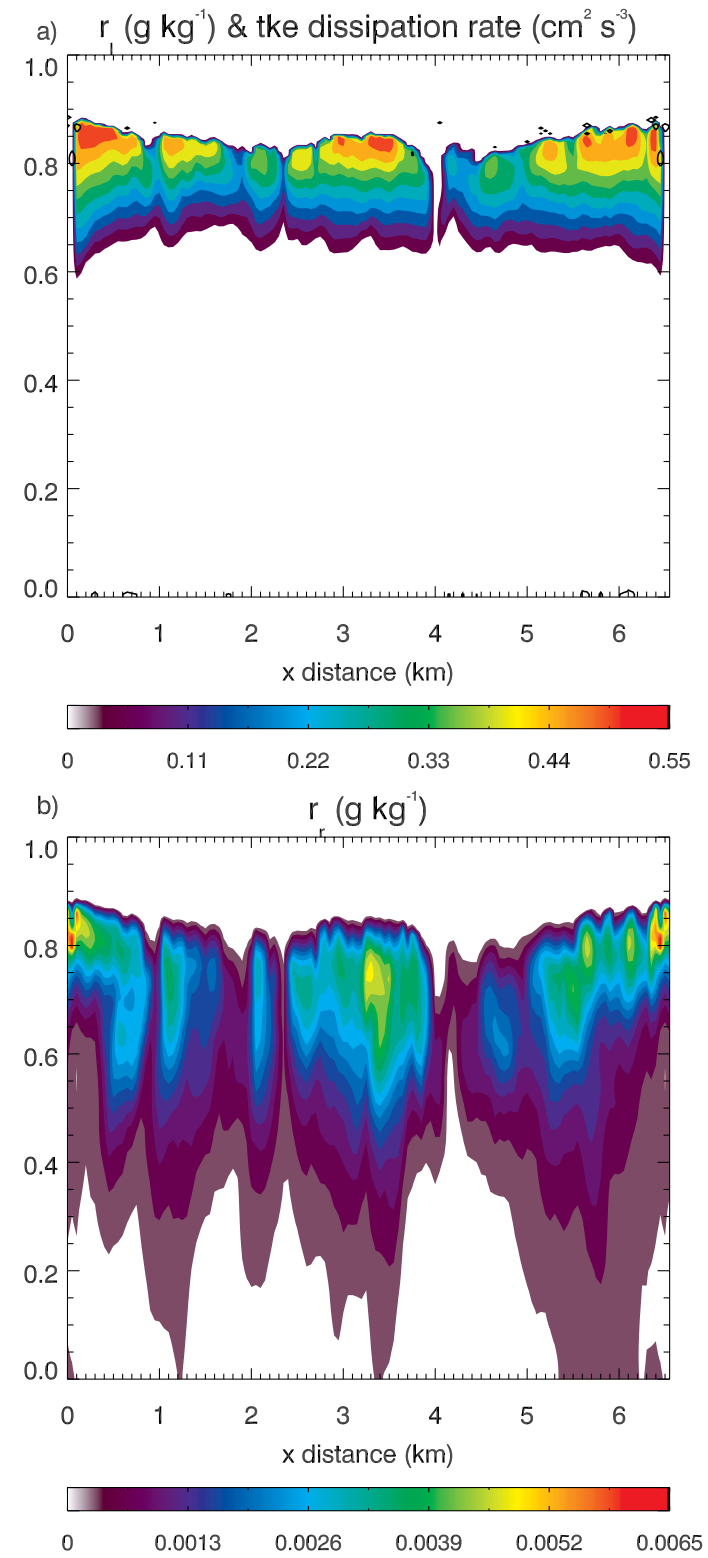

Figure 2. Cross sections of the (a) liquid and (b) rain water mixing ratios $\left(\mathrm{g} \mathrm{kg}^{-1}\right)$ for the DYCOMS II case. Contour lines of the turbulent kinetic energy dissipation rate in (a) are $100 \mathrm{~cm}^{2} \mathrm{~s}^{-3}$.

lation where the non-turbulent parameterisation is used as shown in Fig. 3. The results using the well-known Seifert and Beheng $(2001$; SB) scheme are included as a measure of confidence for the more recent schemes of Franklin (2008), and to give some indication as to the uncertainties due to different bulk scheme parameterisations. However, the main focus is on the differences between the turbulent and non-turbulent microphysics schemes that have been derived using the same framework.

The rain water mixing ratios are significantly increased when the turbulent microphysics effects are included, with 

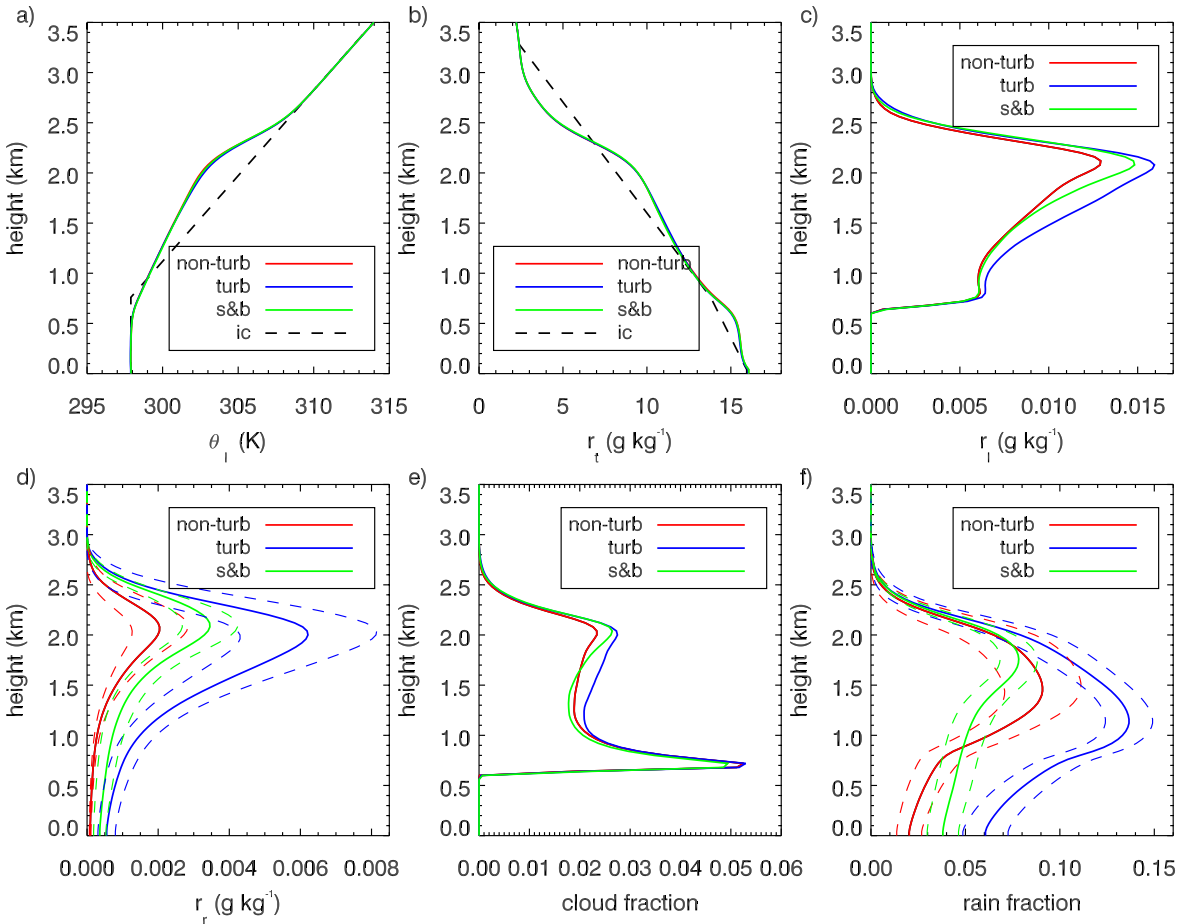

Figure 3. RICO cloud properties for the simulations that use the turbulent (blue) and non-turbulent (red) microphysics parameterisations of Franklin (2008) and the microphysics scheme of Seifert and Beheng (2001; green). The initial conditions are given by the black dashed lines. (a) Liquid water potential temperature $(\mathrm{K})$, (b) total water mixing ratio $\left(\mathrm{g} \mathrm{kg}^{-1}\right)$, (c) liquid water mixing ratio $\left(\mathrm{g} \mathrm{kg}^{-1}\right)$, (d) rain water mixing ratio $\left(\mathrm{g} \mathrm{kg}^{-1}\right)$, (e) cloud fraction and (f) rain fraction. The coloured dashed lines in (d) and (f) represent the \pm standard deviation from the temporal means, with these fields being the only ones that show significantly different means.

the largest difference occurring at the surface where the turbulent case produces 6 times more rain than the non-turbulent case and 1.5 times more than the simulation with the SB microphysics scheme. While there is a large amount of temporal variability in the rain water profiles as shown by the standard deviations in Fig. 3d, the comparison between the simulations with the turbulent and non-turbulent microphysics schemes show a statistically significant increase in the rain water throughout all levels except the uppermost $500 \mathrm{~m}$. The surface area experiencing rainfall increases by a factor of 3 , and the rain fraction is also larger throughout the cloud layer in the turbulent microphysics case as compared to the nonturbulent microphysics simulation. The SB simulation produces 1.5 times less raining surface area than the turbulent microphysics simulation and the profile of the rain area fraction in the SB simulation shows a different structure to the other simulations. The two Franklin scheme simulations produce larger increases in the rain fractions with height and demonstrate that the inclusion of turbulence effects on the droplet collision rates has less effect on the rain fraction profile than the parameterisation uncertainties associated with bulk schemes. The profiles of liquid water potential temperature and total water mixing ratio show that the largest difference between the cases occurs near the height of the inversion, with the turbulent microphysics simulation being $0.2 \mathrm{~K}$ warmer than the case with the non-turbulent microphysics (Fig. 3). The largest difference in cloud fraction occurs in the levels above $1000 \mathrm{~m}$, where more cloud water in the turbulent case generates greater cloud fractions. The simulation using the turbulent microphysics parameterisation has on average greater cloud water throughout the cloud. However, the percentage increase in the amount of rain water produced in this simulation compared to the case using the non-turbulent microphysics is far more than the increase in the cloud liquid water contents, and the variability is such that the mean cloud water contents of all the simulations lie within one standard deviation of the mean for the turbulent case.

Quantitatively these results are in agreement with the RICO LES simulations of Seifert et al. (2010) who used a different turbulent collision kernel based on the results of Ayala et al. (2008) and Wang et al. (2008). Wyszogrodzki et al. (2013) used the Ayala et al. (2008) kernel in a bin microphysics scheme to simulate a shallow convection case from the Barbados Oceanographic and Meteorological Experiment (BOMEX). Their LES results show increases of accumulated surface precipitation of between 4 and 12 times depending on the cloud condensation nuclei concentration. Together with the results of this study, all these cases have demonstrated that including the effects of turbulence on the droplet collision rates makes a significant difference to the 


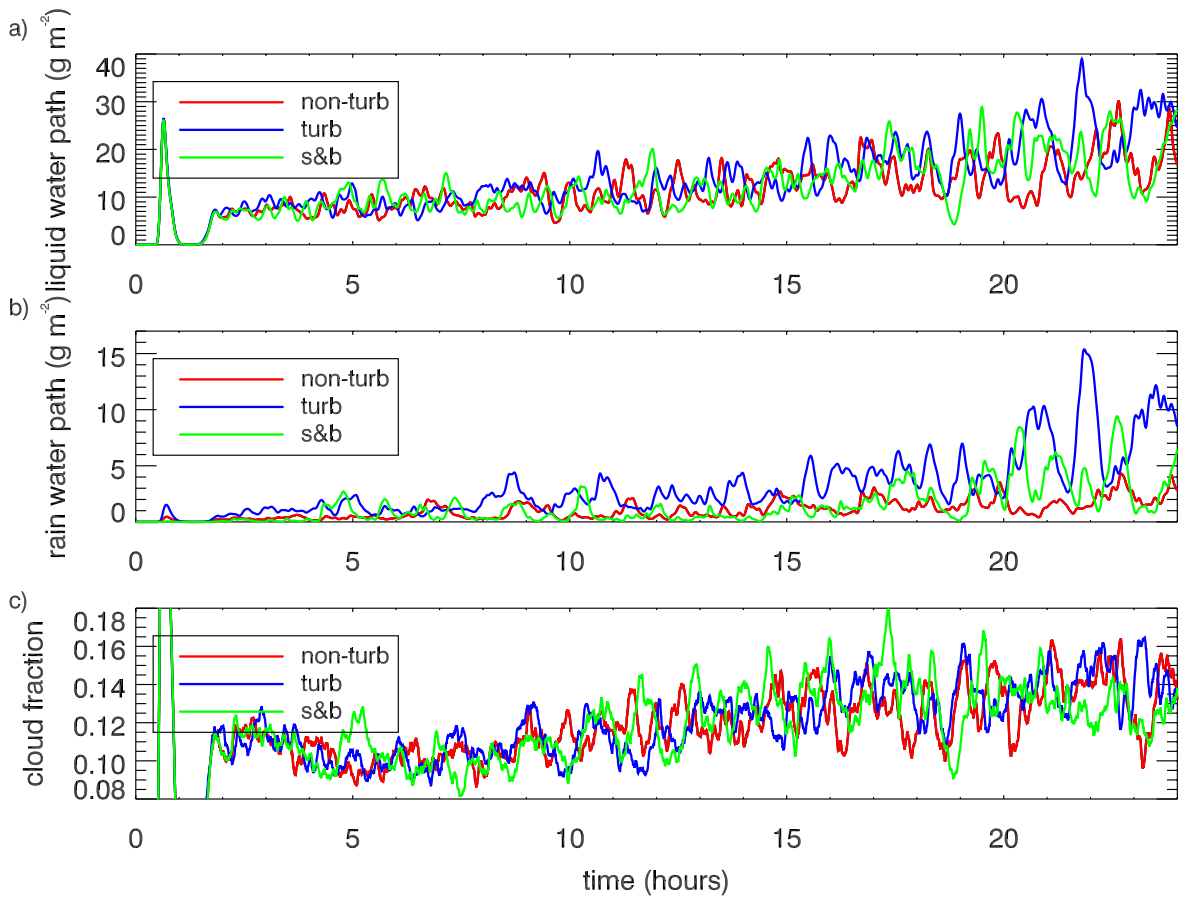

Figure 4. Time series of RICO (a) liquid (cloud and rain) water path $\left(\mathrm{g} \mathrm{m}^{-2}\right)$, (b) rain water path $\left(\mathrm{g} \mathrm{m}^{-2}\right)$ and (c) cloud fraction for the simulations that use the turbulent (blue) and non-turbulent (red) microphysics parameterisations of Franklin (2008) and the microphysics scheme of Seifert and Beheng (2001; green).

amount of rain that shallow convective clouds produce. As discussed in both of the aforementioned publications, the resolution of these simulations is not fine enough to resolve the structure of these clouds. Seifert et al. (2010) tested the sensitivity of their results to a doubling in horizontal resolution and found a substantial reduction in the surface rain rate; however, the turbulence case still produced significantly greater rain.

Time series of the evolution of the liquid water path, rain water path and cloud fractions are shown in Fig. 4. There is a spike during the first hour as the initial cloud field develops, and after about $2 \mathrm{~h}$ the cloud cover reaches $12 \%$. The simulation with the turbulent microphysics shows a greater rain water path than the simulation with the non-turbulent microphysics at almost all times of the $24 \mathrm{~h}$ simulations, with a few significant peaks occurring during the last $4 \mathrm{~h}$. The precipitation intermittency is due to the limited domain size that will only allow for one large rain event at a time (Seifert and Heus, 2013). All simulations show similar variability in the cloud fraction,. However the average liquid water path variance over the last $4 \mathrm{~h}$ is almost double in the turbulent microphysics simulation.

Figure 5 shows that the evaporation of rain water is greatly enhanced in the turbulent microphysics simulation and this is due to an increase in both rain water and rain drop number concentration. The average TKE from the simulation using the turbulent microphysics is less than that of the non- turbulent case in the cloud levels above $2 \mathrm{~km}$. However, in the lower levels including below cloud base, the TKE from the turbulent case is greater than the non-turbulent case. The increased TKE in the subcloud layer of the simulation that includes the turbulence effects on droplet collisions reflects the greater horizontal variability associated with the enhanced evaporation of precipitation destabilising the levels below the cloud (Fig. 5d). In the turbulent microphysics simulation the reduced TKE in the upper regions of the cloud is caused by a reduction in the buoyancy production of TKE (Fig. 5c). In this case there is an increase in water loading associated with the increased cloud and rain water, particularly in these upper levels. This increase in water loading reduces the buoyancy production of TKE (Fig. 5c) and reduces the amount of TKE that is transported to the inversion layer that is required for entrainment (Jiang and Cotton, 2000).

The reduced buoyancy production of TKE in the upper levels of the cloud in the turbulent case is associated with a reduction in the variance of the vertical motion (Fig. 5e). The updrafts within the clouds in the turbulent case are stronger in the upper levels due to the increased latent heating associated with the larger generation of cloud liquid water. This is also reflected in the more positive values of the third moment of vertical velocity in the turbulent microphysics case, indicating smaller, more intense updrafts and larger weaker downdrafts (not shown). These stronger in-cloud vertical velocities occur above the height of the maximum theta gradient 

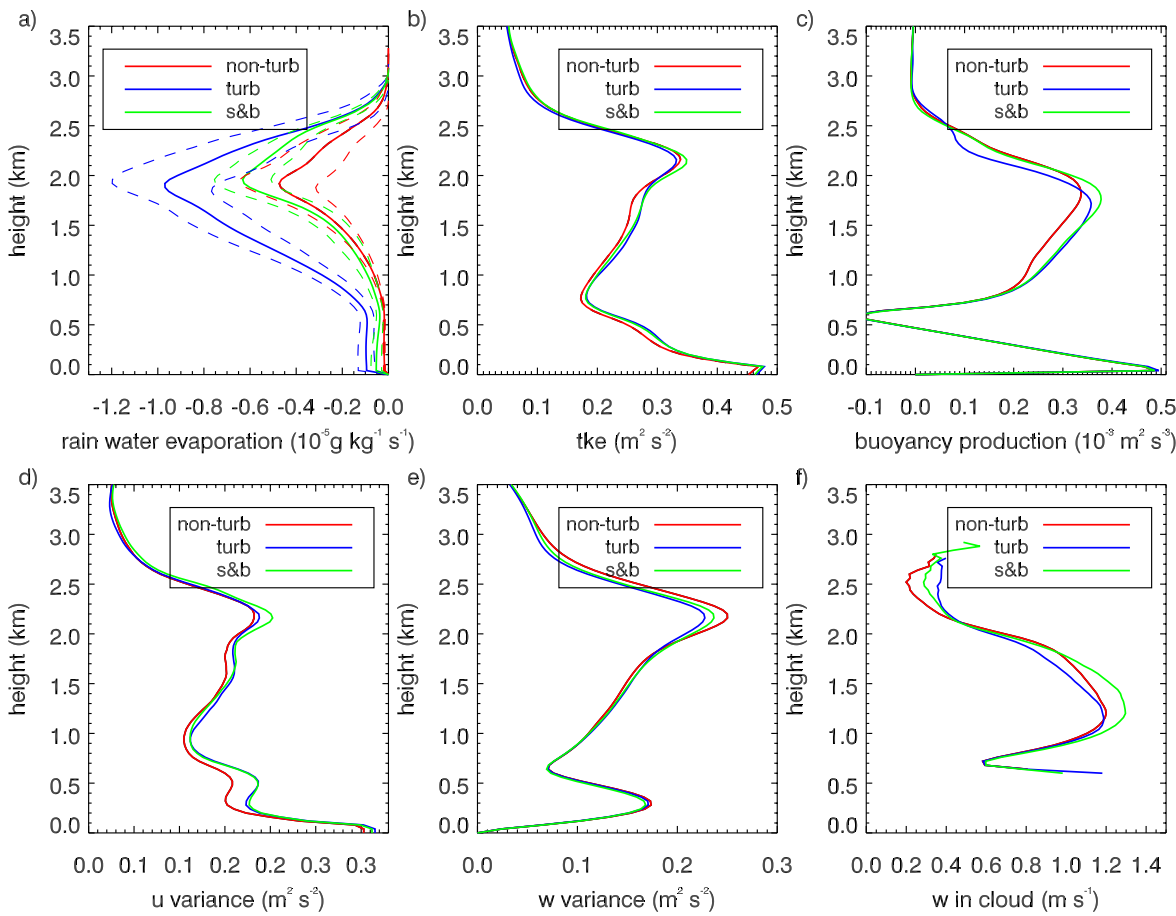

Figure 5. As in Fig. 3 except for (a) rain water evaporation $\left(\mathrm{g} \mathrm{kg}^{-1} \mathrm{~s}^{-1}\right)$, (b) turbulent kinetic energy $\left(\mathrm{m}^{2} \mathrm{~s}^{-2}\right)$, (c) buoyancy production of turbulent kinetic energy $\left(10^{-4} \mathrm{~m}^{2} \mathrm{~s}^{-3}\right)$, (d) variance of $u$ component of horizontal wind $\left(\mathrm{m}^{2} \mathrm{~s}^{-2}\right),(\mathbf{e})$ variance of vertical velocity $\left(\mathrm{m}^{2} \mathrm{~s}^{-2}\right.$ ) and (f) conditional average of vertical velocity inside clouds $\left(\mathrm{m} \mathrm{s}^{-1}\right)$. The coloured dashed lines in (a) represent the \pm standard deviation from the temporal means, with the rain water evaporation being the only field that shows significantly different means.

(2321 $\mathrm{m}$ in the non-turbulent case and $2328 \mathrm{~m}$ in the turbulent microphysics case) and reflect the stronger overshooting convection in the turbulent case. Wyszogrodzki et al. (2013) argued that the use of turbulent collision kernels produces a dynamical enhancement to the amount of precipitation generated due to the off-loading of condensed water, which in turn increases buoyancy and cloud top heights. In our case the water loading reduces the buoyancy in the upper levels of the cloud but increases the buoyancy below about $1800 \mathrm{~m}$. Jiang and Cotton (2000) examined the differences between drizzling and non-drizzling shallow convective clouds and also found a reduction in buoyancy and turbulence in their case with larger precipitation.

To further examine the buoyancy characteristics of the clouds and estimate the entrainment rates, the conditional averages of vertical velocity, total and liquid water contents within cloud cores are analysed. Cloud cores are defined as the cloudy regions that have positive buoyancy as compared to the slab average. Figure 6a shows that the simulation with the turbulent microphysics has a larger area of cloud cores throughout the mid and upper cloud levels as compared to the simulation with the non-turbulent microphysics. However, comparing these profiles to Fig. 3e, we see that the turbulent microphysics case has a smaller proportion of positively buoyant cloud regions in the levels above $1300 \mathrm{~m}$. The average vertical velocities in the cloud core are very similar in the simulations with the non-turbulent and turbulent microphysics schemes, with the turbulent case having slightly weaker updrafts in the upper cloud core levels. This result together with the vertical velocities averaged over all cloudy regions shown in Fig. 5f, shows that the turbulent microphysics simulation has increased vertical velocities in the cloudy regions that are not positively buoyant. This demonstrates that in this simulation it is not the reduced water loading associated with greater precipitation that acts to increase the buoyancy and hence the vertical velocities. Figure $6 \mathrm{c}$ shows that the turbulent microphysics simulation has larger average total water contents in the cloud core upper levels and this applies to the cloud liquid water as well (Fig. 6d). Diagnosing the mass flux and fractional entrainment rates using Eqs. (11) and (16) of Stevens et al. (2001) and the total moisture mixing ratio, shows that the mass flux in the upper levels is larger for the turbulent microphysics simulation (Fig. 6e) and this is due to the greater area of the cloud cores in this case. The turbulent microphysics simulation has a smaller entrainment rate throughout the vertical compared to the simulation with the non-turbulent microphysics parameterisations, in agreement with the larger water contents in the simulation that includes the effects of turbulence on the droplet collision rates. Note that the application of the mass flux approach with a simple entraining plume model breaks down in the inversion 

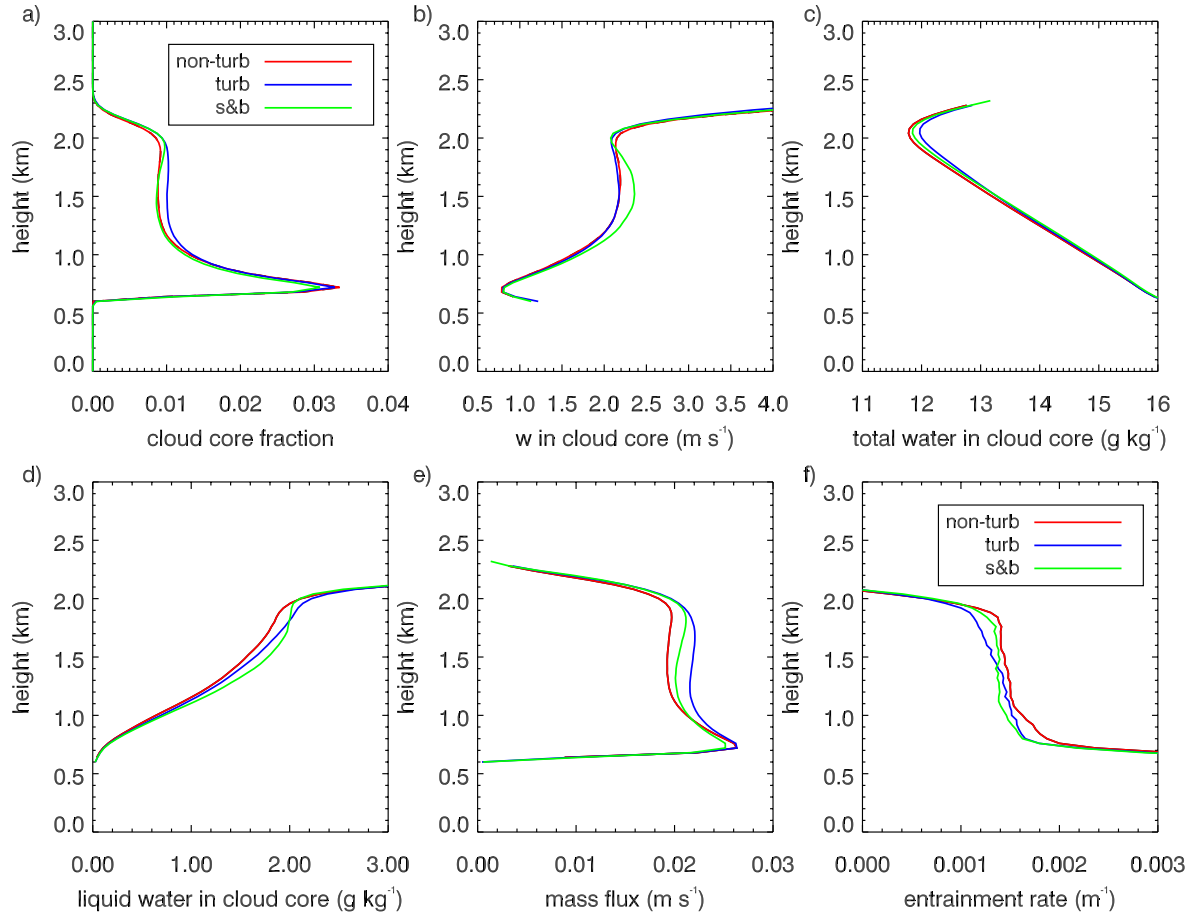

Figure 6. As in Fig. 3 except for (a) cloud core fraction, (b) conditional average of vertical velocity inside cloud cores ( $\left.\mathrm{m} \mathrm{s}^{-1}\right)$, (c) conditional average of total water inside cloud cores $\left(\mathrm{g} \mathrm{kg}^{-1}\right)$, (d) conditional average of cloud liquid water in cloud cores $\left(\mathrm{g} \mathrm{kg}^{-1}\right),(\mathbf{e}) \mathrm{mass}$ flux $\left(\mathrm{m} \mathrm{s}^{-1}\right)$, and (f) entrainment rate $\left(\mathrm{m}^{-1}\right)$.

at about $2 \mathrm{~km}$ (Siebesma et al., 2003) and explains the sharp gradient in Fig. 6f.

The effect of the dynamical feedback in the RICO case presented here is a negative feedback on the turbulent enhancement of rain water generation. The reduced buoyancy production of TKE in the upper cloud levels where most of the liquid water is located (Figs. 1 and 3), reduces the TKE and dissipation rate of TKE compared to the simulation with the non-turbulent microphysics. Given that the turbulent enhancement is a function of the dissipation rate of TKE, the use of the turbulent microphysics parameterisations acts to reduce the dissipation rate in the cloud levels where the liquid water contents are largest and hence produces a negative feedback. It should be recognised that there is still a significant enhancement of rain water compared to the nonturbulent case and the increased cloud depths discussed by Wyszogrodzki et al. (2013) are present in our simulations. Maximum cloud top heights are larger in the turbulent microphysics simulation compared to the non-turbulent; on average the highest cloud top is $2656 \mathrm{~m}$ compared to $2620 \mathrm{~m}$. However, in this case the impact of the enhanced cloud and rain water acts to reduce the TKE rather than promote larger buoyancy production of TKE.

The effect of this negative feedback can be seen in Fig. 7 where the dissipation rates of TKE are shown for the control simulations and sensitivity tests where the cloud droplet number concentration was reduced from 70 to $40 \mathrm{~cm}^{-3}$. In

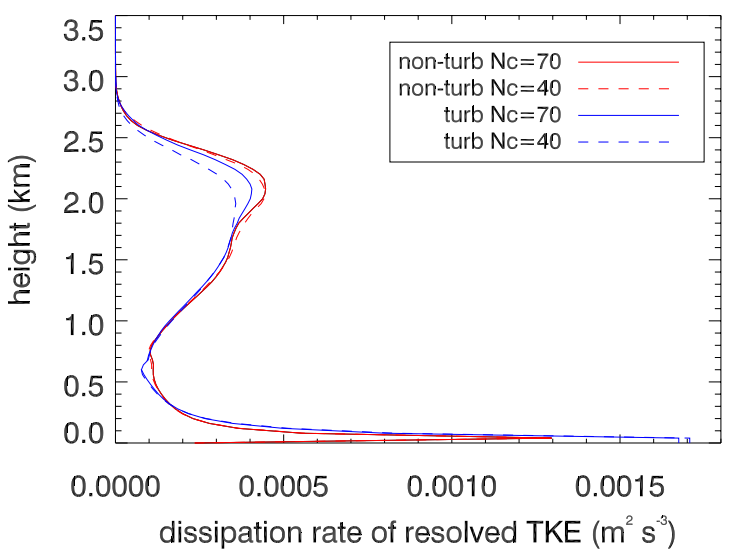

Figure 7. Dissipation rate of resolved TKE $\left(\mathrm{m}^{2} \mathrm{~s}^{-3}\right)$ for the nonturbulent and turbulent microphysics simulations for the control $\left(N_{\mathrm{c}}\right.$ $=70$ ) and a reduced cloud droplet number concentration of $N_{\mathrm{c}}=$ $40 \mathrm{~cm}^{-3}$.

the simulations with the reduced number concentration the amount of rain water is increased from the control, with the average rain water path in the non-turbulent microphysics simulations increasing from 1.9 to $4.3 \mathrm{~g} \mathrm{~m}^{-2}$, and 7.9 to $10.6 \mathrm{~g} \mathrm{~m}^{-2}$ for the turbulent microphysics simulations. Figure 6 shows the reason why the percentage increase in rain water path is larger for the non-turbulent microphysics case, 

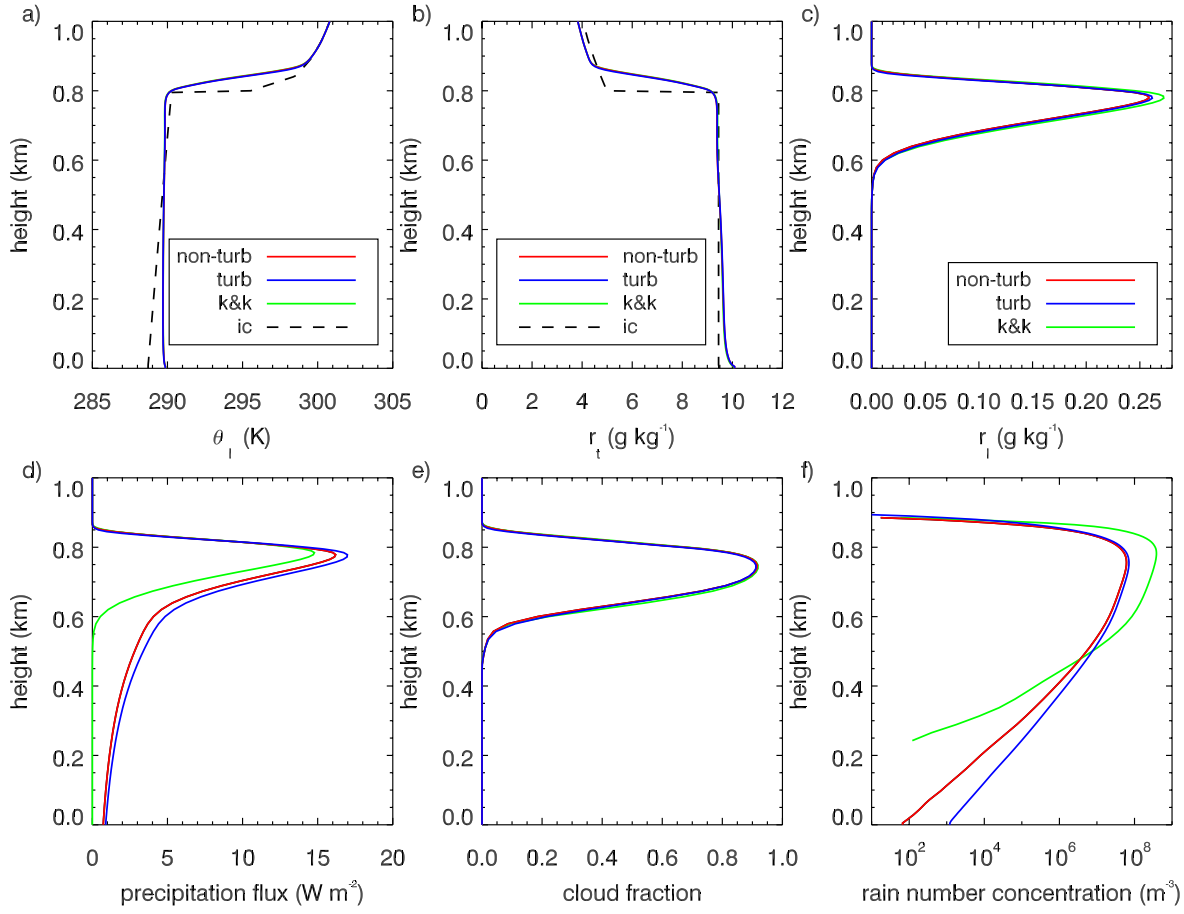

Figure 8. DYCOMS II cloud and dynamical properties for the simulations that use the turbulent (blue) and non-turbulent (red) microphysics parameterisations of Franklin (2008) and the microphysics scheme of Khairoutdinov and Kogan (2000; green). The initial conditions are represented by the black dashed line. (a) Liquid water potential temperature $(\mathrm{K})$, (b) total water mixing ratio $\left(\mathrm{g} \mathrm{kg}^{-1}\right)$, (c) liquid water mixing ratio $\left(\mathrm{g} \mathrm{kg}^{-1}\right)$, (d) precipitation flux $\left(\mathrm{W} \mathrm{m}^{-2}\right)$, (e) cloud fraction and (f) rain drop number concentration $\left(\mathrm{m}^{-3}\right)$.

and this is due to a reduction in the dissipation rate of TKE in the turbulent microphysics simulations due to the negative feedback from the buoyancy generation of TKE, which limits the enhancement from the turbulent microphysics as the rain and cloud water increase.

\subsection{Stratocumulus - RF02 of DYCOMS II}

Similar to the shallow convection case, the dissipation rates of TKE that affect the microphysics are maximum in the upper levels of the stratocumulus cloud layer; however, for this case the dissipation rates are much weaker (Fig. 2). There are only small regions at the top of the cloud where the dissipation rate reaches $100 \mathrm{~cm}^{2} \mathrm{~s}^{-3}$ and, therefore, where the conversion rates between cloud and rain water will be accelerated by turbulence effects in the simulation that uses the turbulent microphysics. These small regions though do make a difference to the precipitation flux and the rain drop number concentration in the cloud and subcloud layers, while the cloud fractions remain relatively unchanged (Fig. 8). The average rainwater path increases by $17 \%$ when the turbulent microphysics parameterisations are used; however, the variability is such that this is not a statistically significant result. For this case the microphysics scheme of Khairoutdinov and Kogan (2000; KK) has been used as a comparison for the new schemes, since this scheme was developed specifically for stratocumulus clouds.
For this lightly drizzling case the precipitation flux is maximum at cloud top (Fig. 8). The increased rain water in the turbulent microphysics simulation is associated with a greater number of rain drops and larger evaporation rates of rain water, particularly just below cloud base (Fig. 9a). The precipitation from the KK scheme does not reach the surface in this case and has a reduced precipitation flux at all levels compared to the schemes of Franklin. Figures $8 \mathrm{f}$ and $9 \mathrm{a}$ show that the rain number concentration is larger in the $\mathrm{KK}$ simulations throughout the cloud layer, and that these more numerous rain drops produce larger evaporation rates at both cloud top and cloud base. Examining the cloud and rainfall properties for the three simulations shows that for this stratocumulus case the parameterisation uncertainties for a bulk scheme are larger than the effects of turbulence.

Comparing the simulations that use the turbulent and nonturbulent microphysics schemes of Franklin, shows that the effects of turbulence on the droplet collision rates increases the evaporation of rain water and leads to greater variability and higher TKE throughout both the cloud and subcloud layers. The enhanced rain water in the turbulent microphysics simulation has a weak positive feedback, with more rain producing more evaporation of drizzle drops at cloud base, which destabilises the subcloud layer and leads to stronger circulations and TKE (Feingold et al., 1996). The observations for this case showed that the vertical winds were 

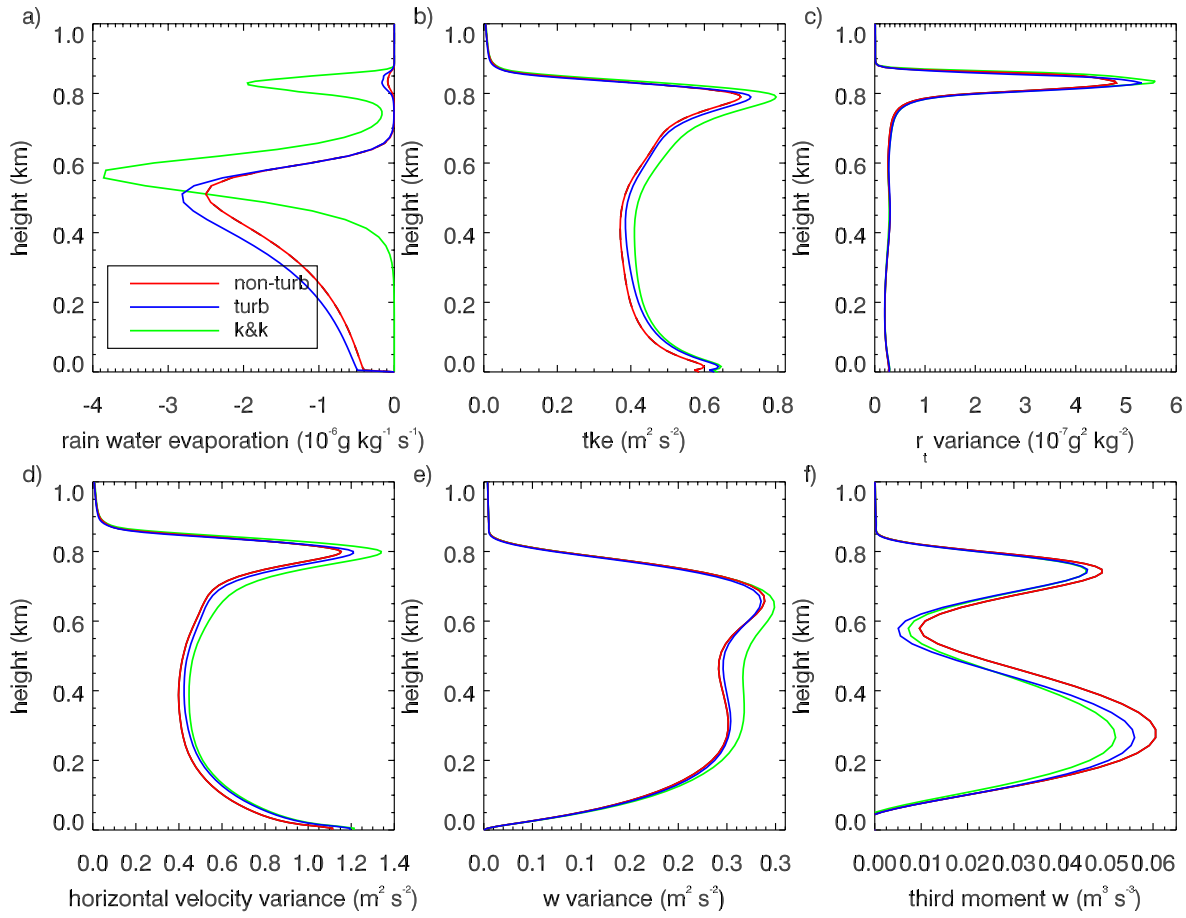

Figure 9. As in Fig. 6 expect for (a) rain water evaporation $\left(\mathrm{g} \mathrm{kg}^{-1} \mathrm{~s}^{-1}\right)$, (b) turbulent kinetic energy $\left(\mathrm{m}^{2} \mathrm{~s}^{-2}\right)$, (c) variance of liquid water $\left(\mathrm{g}^{2} \mathrm{~kg}^{-2}\right)$, (d) variance of horizontal velocity $\left(\mathrm{m}^{2} \mathrm{~s}^{-2}\right)$, (e) variance of vertical velocity $\left(\mathrm{m} \mathrm{s}^{-1}\right)$ and (f) third moment of vertical velocity $\left(\mathrm{m} \mathrm{s}^{-1}\right)$.

negatively skewed just above cloud base (Ackerman et al., 2009) and the simulation with the turbulent microphysics produces a closer match with nearly equal strength between updrafts and downdrafts at this height (Fig. 9f).

\section{Sensitivity to cloud droplet number concentrations}

Four simulations of the stratocumulus and shallow convection cases were performed with each of the non-turbulent and turbulent microphysics parameterisations. The simulations differ in the prescribed CDNC and reveal how the cloud properties change with changes in aerosol loading as manifested in changes of cloud droplet number. These simulations are not designed to reflect the complete aerosol-cloud interactions but rather to provide some insights into whether the effects of turbulence on cloud droplet interactions negate some of the reduction in precipitation that tends to occur with increasing cloud droplet number concentrations and the associated decrease in precipitation efficiency.

Figure 10 shows the average cloud properties over the last $4 \mathrm{~h}$ of the RF02 simulations of DYCOMS II, with the standard deviations shown by the bars. The cloud fraction increases monotonically for both the non-turbulent and turbulent cases as the CDNC increases from 25 to $220 \mathrm{~cm}^{-3}$. There is a strong relationship between increasing cloud fraction and decreasing rain water path as the CDNC is increased. This result for a drizzling stratocumulus cloud agrees with the conceptual model that greater aerosol loading and associated CDNC suppresses precipitation formation and leads to larger cloud fractions (Albrecht, 1989). For the CDNC values explored here, the non-turbulent microphysics simulations demonstrate that stratocumulus clouds typical of this case study increase the amount of cloud water and reduce the rain water content when there is an increase in cloud droplet number. Therefore, they show a positive second aerosol indirect effect (Fig. 10b; Stevens et al., 1998). While this is also true for the lowest three CDNC used in this study for the turbulent microphysics simulations, for the highest concentration of 220 droplets $\mathrm{cm}^{-3}$ the turbulent microphysics simulation shows a reduction in both the rain and liquid water paths. The reduced rain water leading to a reduced liquid water path in the turbulent microphysics simulation with highest CDNC shows a negative second aerosol indirect effect. Other studies have also shown a non-monotonic increase in liquid water path (LWP) with increasing aerosol concentrations and suggest that there is a limit to the degree of liquid water that can build up, with increasing efficiency of evaporation due to larger concentrations of smaller drops likely playing a role (Xue et al., 2008). However, in this case the variability of the liquid water paths is significantly larger than the small reduction in liquid water path for the highest CDNC and, therefore, this is unlikely to be a robust physical result for this simulation. 

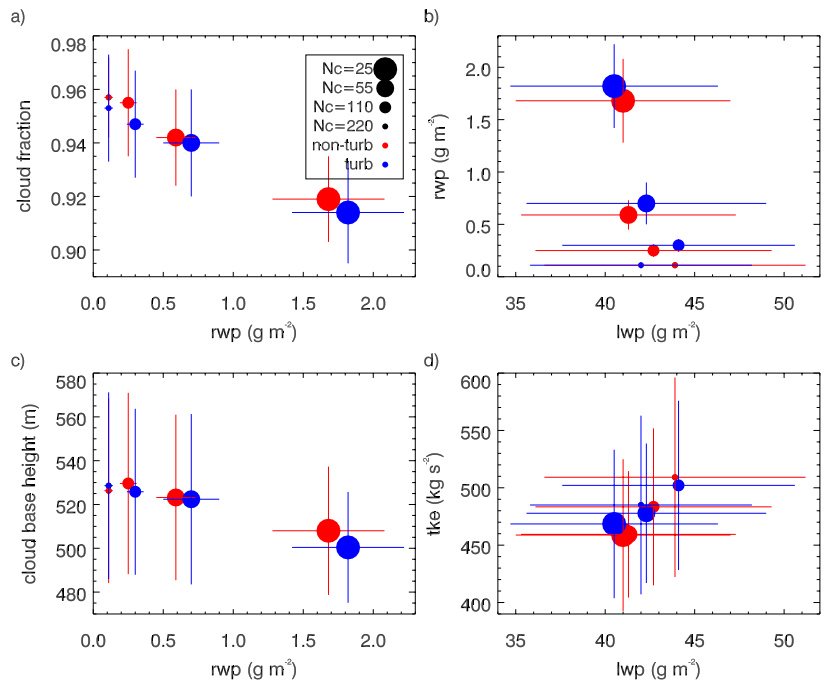

Figure 10. Average DYCOMS II cloud and dynamical properties for specified CDNC. Rain water path $\left(\mathrm{g} \mathrm{m}^{-2}\right)$ and (a) cloud fraction and (c) cloud base height $(\mathrm{m})$. Liquid water path $\left(\mathrm{g} \mathrm{m}^{-2}\right)$ and (b) rain water path $\left(\mathrm{g} \mathrm{m}^{-2}\right)$ and (d) vertically integrated turbulent kinetic energy $\left(\mathrm{kg} \mathrm{s}^{-2}\right)$. The length of the bars denote the \pm standard deviations about the mean.

Figure 10c shows that there is an increase in the cloud base heights as cloud droplet numbers are increased and precipitation is decreased. This has been found before, for example by Savic-Jovcic and Stevens (2008), who showed that cloud base lowers in regions of precipitation due to the precipitation changes affecting the thermodynamic state of the subcloud layer. This can be seen through the tendency of the TKE to increase with CDNC in all simulations except for the turbulent case with highest CDNC (Fig. 10d). An important aspect for this work is that the TKE is greater for the turbulent microphysics simulations compared to the corresponding non-turbulent simulation for each CDNC, except for the case with the largest CDNC where the behaviour changes due to a reduction in liquid water path. These results reflect the positive feedback that the turbulent microphysics parameterisations have on increasing the TKE, which will then produce greater precipitation. However, these results need to be interpreted with caution due to the large variability shown in the liquid water path and TKE fields. Xue and Feingold (2006) studied the impact of increasing aerosol concentrations on shallow cumuli cloud properties and found that the influence from aerosols was less than the dynamical variability of the system in all fields examined except for the cloud optical depths. This result is seen in Fig. 10 where it can be seen that the variability in all of the fields is large compared to the changes due to either the inclusion of turbulence effects or the CDNC. The rain water path is the only field that shows a significant change in rain water with changes in the CDNC. For this stratocumulus case the effects of turbulence
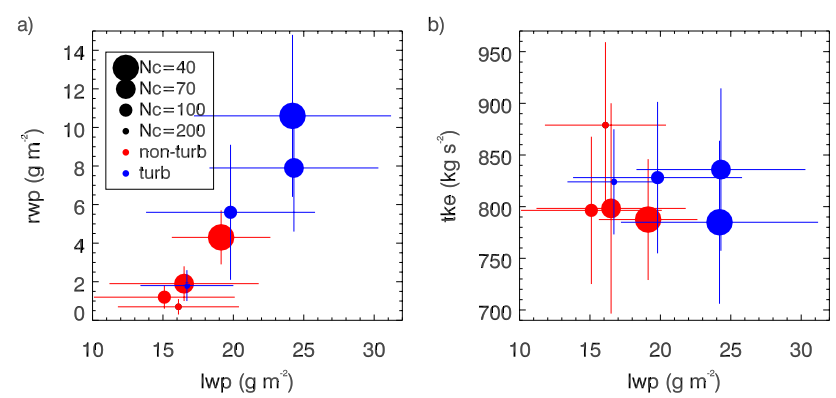

Figure 11. Average RICO cloud and dynamical properties for specified CDNC. Liquid water path $\left(\mathrm{g} \mathrm{m}^{-2}\right)$ and (a) rain water path $\left(\mathrm{g} \mathrm{m}^{-2}\right)$, and (b) vertically integrated turbulent kinetic energy $\left(\mathrm{kg} \mathrm{s}^{-2}\right)$. The length of the bars denote the \pm standard deviations about the mean.

on rainfall are not statistically significant and instead it is the CDNC that has the largest control on the rain water.

Figure 11 shows the effects of increasing the CDNC in the RICO simulations. In this shallow cumulus convection case the liquid water path increases as the rain water path increases, which is the opposite of the stratocumulus case. Increased CDNC results in reduced rainwater in both cases, but in the RICO cases this also results in reduced liquid water paths. The increased CDNC will tend to slow the collisioncoalescence process, enhance evaporation and reduce the drop fall speeds (Xue and Feingold, 2006). The result of this and the subsequent feedbacks in these small clouds is to reduce the liquid water path as well as the amount of precipitation. Therefore, for this case all simulations produce a negative second aerosol indirect effect, except for the highest CDNC using the non-turbulent microphysics scheme, which shows a small increase in liquid water path. The change in average cloud fraction for all simulations is small and generally less than $1 \%$. As shown in Xue et al. (2008) this may be due to the cancellation of changes in cloud size and cloud frequency.

The TKE response to increased CDNC in the shallow cumulus convection case is shown in Fig. 11b. Both sets of simulations tend to show an increase in vertically averaged TKE as CDNC increases, with the largest changes occurring for the smallest CDNC in the turbulent microphysics set and the highest CDNC in the non-turbulent set. The simulation that produces the largest TKE is the non-turbulent microphysics scheme case with the highest CDNC. This is due to a significant increase in the vertical velocity variance and buoyancy production of TKE, which is responsible for the liquid water path being larger in this case than the simulation with CDNC of $100 \mathrm{~cm}^{-3}$. Examining the profiles of buoyancy production of TKE for the non-turbulent microphysics cases shows that the reduction in vertically integrated TKE as CDNC reduces and rain water increases is due to the negative feedback that the enhanced precipitation has on the buoyancy production of TKE, as discussed previously. Figure 11 shows that 
the liquid water paths almost converge for the turbulent and non-turbulent simulations with the largest CDNC due to the similar smaller rain water paths and the reduced effect of the turbulence-enhanced autoconversion and accretion rates.

\section{Summary}

Use of the bulk warm rain microphysics parameterisations of Franklin (2008) in the UCLA-LES has allowed an investigation into the effects of turbulence on cloud droplet collisioncoalescence in stratocumulus and shallow convective clouds. The microphysics parameterisations that include the effects of turbulence on droplet collision rates had a greater impact on the simulated precipitation rates in the shallow convection case, where the larger dissipation rates of TKE produced a more rapid conversion of cloud water to rain water. The amount of rain water reaching the surface was six times larger in the simulation with the turbulent microphysics scheme. The much weaker dissipation rates in the stratocumulus case, however, also showed a change in the simulated precipitation when the effects of turbulence on microphysical processes were included in the model, with rain water paths increasing by $17 \%$. However, unlike the shallow convection case, this is not a statistically significant result.

Both cases using the turbulent microphysics scheme produced greater evaporation rates of rain water, which caused a change in the thermodynamics of the subcloud layer, destabilising the lower levels and enhancing the horizontal variability and TKE in this region. The difference in the precipitation-dynamical feedbacks between the two cases was in the upper levels of the clouds where the liquid water contents are largest. In the shallow convection case the greater rain and cloud water loading and enhanced latent heating associated with the larger liquid water in the turbulent microphysics simulation, reduced the buoyancy production of TKE and the entrainment. Therefore, in this case a negative precipitation-dynamical feedback to the enhanced precipitation formation associated with turbulent microphysics effects was produced. In contrast, the stratocumulus case showed a weak positive feedback, with enhanced rainwater and rain water evaporation in the simulation with the turbulent microphysical parameterisations producing greater TKE in both the subcloud layer and in the upper cloud region. Including the results from the other bulk microphysics schemes (Seifert and Beheng for the RICO case and Khairoutdinov and Kogan for the DYCOMSII case) demonstrated that including the effects of turbulence on droplet collision rates had a larger impact than the different microphysics scheme for the shallow convection case, but that the opposite is true for the stratocumulus case. These results highlight the significant parameterisation uncertainties associated with bulk schemes in their simulations of stratocumulus clouds.
Sensitivity studies where the CDNC was varied showed agreement with the conceptual model for lightly drizzling stratocumulus clouds, that greater CDNC suppresses precipitation formation leading to larger cloud fraction and liquid water paths (Albrecht, 1989). This can be interpreted as a positive second indirect aerosol effect, and was produced in all of the DYCOMS II simulations except for the case using the turbulent microphysics with the highest CDNC which showed a small reduction in liquid water path. The RICO shallow convection case produced a negative second indirect aerosol effect in all but one simulation. The increased CDNC in the small convective clouds reduced the production of rainwater, enhanced the evaporation and led to a reduction in the liquid water path. While the sign of the second indirect effect is negative in the shallow convection case whether the effects of turbulence on cloud droplet collisions are considered or not, the magnitude of the effect is doubled when the turbulent microphysics are used. Liquid water paths reduce from 19.1 to $16.1 \mathrm{~g} \mathrm{~m}^{-2}$ for the non-turbulent microphysics simulations as CDNC increases from 40 to $200 \mathrm{~cm}^{-3}$, whereas for the turbulent microphysics simulations the liquid water paths change from 24.2 to $16.7 \mathrm{~g} \mathrm{~m}^{-2}$.

The results presented in this work are by no means a definitive or quantitative statement as to how the effects of turbulence on cloud collision and coalescence impacts precipitation and cloud properties. Larger domains and higher resolution simulations need to be conducted in the future to test how robust the features are that have been described in this study. Seifert et al. (2010) performed a set of simulations at double the horizontal resolution of their control case and found a reduction in the rainfall increase due to turbulent enhancement. How this may change with further refinement of the computational grid remains to be seen. Matheou et al. (2011) found that the negative buoyancy zones that occur at the cloud-environment interface are unresolved for typical LES resolutions and discussed the impact that this may have on modelling the entrainment process. Higher resolution simulations that better resolve entrainment could show a change in the buoyancy and entrainment results found in this study. In addition, other case studies and thermodynamic profiles should be tested to investigate the sensitivity of the effects to changes in the large-scale environment. Refinements and further developments to the turbulent collision kernels and collision efficiencies are also required to advance the knowledge regarding the effects of turbulence on cloud microphysics, the formation of precipitation and the precipitation-dynamical feedbacks. Wyszogrodzki et al. (2013) describe their aims of developing an integrated multiscale computational approach that combines LES and DNS approaches. This would provide a unique way to simulate the wide range of scales involved with precipitation formation from kilometres to millimetres.

As discussed by Savic-Jovcic and Stevens (2008), often LES require lower CDNC than observed to initiate precipitation, and this includes both bulk and bin models. Including 
the effects of turbulence in the microphysics parameterisations minimises this need to artificially reduce CDNC in order to simulate observed precipitation rates. How much of this effect may be due to a better physical representation of the collision process or to numerical limitations is an open question. Use of observations to try to answer this would be a worthwhile endeavour; however, as noted by Xue and Feingold (2006), the variability of the cloud fields in shallow convection simulations where the impact of the turbulence enhancement is largest might make this somewhat challenging. For example, the changes to liquid water paths due to the effects of turbulent microphysics are much smaller than the standard deviations of the liquid water path of any given simulation by about an order of magnitude. In this study the analysis of the turbulent enhancement and the precipitationdynamical feedbacks has been on a scale larger than that of an individual cloud. Future work will investigate individual cloud properties and life cycles to examine the effects that the microphysics parameterisations that include the effects of turbulence may have on the cloud scale.

Acknowledgements. This research is funded by the Australian Government Department of the Environment, the Bureau of Meteorology and CSIRO through the Australian Climate Change Science Program. Bjorn Stevens from the Max Planck Institute for Meteorology is thanked for providing the UCLA LES model code. Three anonymous reviewers are thanked for providing insightful and constructive comments that helped to improve the paper.

Edited by: G. Feingold

\section{References}

Ackerman, A. S., vanZanten, M. C., Stevens, B., Savic-Jovcic, V., Bretherton, C. S., Chlond, A., Golaz, J.-C., Jiang, H., Khairoutdinov, M., Krueger, S. K., Lewellen, D. C., Lock, A., Moeng, C.-H., Nakamura, K., Petters, M. D., Snider, J. R., Weinbrecht, S., and Zuluaf, M.: Large-eddy simulations of a drizzling, stratocumulus-topped marine boundary layer, Mon. Wea. Rev., 137, 1083-1110, 2009.

Albrecht, B. A.: Aerosols, cloud microphysics, and fractional cloudiness, Science, 245, 1227-1230, 1989.

Ayala, O., Rosa, B., Wang, L.-P., and Grabowksi, W.: Effects of turbulence on the geometric collision rate of sedimenting droplets. Part 2. Theory and parameterization, New J. Phys., 10, 075016, doi:10.1088/1367-2630/10/7/075016, 2008.

Beard, K. V. and Ochs, H. T.: Warm-rain initiation: An overview of microphysical mechanisms, J. Appl. Meteor., 32, 608-625, 1993

Feingold, G., Cotton, W. R., Stevens, B., and Frisch, S. A.: The relationship between in-cloud residence time and drizzle production in numerically simulated stratocumulus clouds, J. Atmos. Sci., 53, 1108-1122, 1996.

Franklin, C. N.: A warm rain microphysics parameterisation that includes the effects of turbulence, J. Atmos. Sci., 65, 1795-1816, 2008 .
Franklin, C. N., Vaillancourt, P. A., Yau, M. K., and Bartello, P. Collision rates of cloud droplets in turbulent flow, J. Atmos. Sci., 62, 2451-2466, 2005.

Franklin, C. N., Vaillancourt, P. A., and Yau, M. K.: Statistics and parameterisations of the effect of turbulence on the geometric collision kernel of cloud droplets, J. Atmos. Sci., 64, 938-945, 2007.

Grabowski, W. W. and Wang, L.-P.: Growth of cloud droplets in a turbulent environment, Ann. Rev. Fluid Mechanics, 45, 293-324, 2013.

Jiang, H. and Cotton, W. R.: Large eddy simulation of shallow cumulus convection during BOMEX: Sensitivity to microphysics and radiation, J. Atmos. Sci., 57, 582-594, 2000.

Khairoutdinov, M. and Kogan, Y.: A new cloud physics parameterisation in a large-eddy simulation model of marine stratocumulus, J. Atmos. Sci., 57, 229-243, 2000.

Kunnen, R. P. J., Siewert, C., Meinke, M., Schröder, W., and Beheng, K. D.: Numerically determined geometric collision kernels in spatially evolving isotropic turbulence relevant for droplets in clouds, Atmos. Res., 127, 8-21, 2013.

Matheou, G., Chung, D., Nuijens, L., Stevens, B., and Teixeira, J.: On the fidelity of large-eddy simulation of shallow precipitating cumulus convection, Mon. Wea. Rev., 139, 2918-2939, 2011.

Pinsky, M. B., Khain, A. P., Grits, B., and Shapiro, M.: Collisions of small drops in a turbulent flow. Part III: Relative droplet fluxes and swept volumes, J. Atmos. Sci., 63, 2123-2139, 2006.

Rauber, R. M., Ochs, H. T., Di Girolamo, L., Göke, S., Snodgrass, E., Stevens, B., Knight, C., Jensen, J. B., Lenschow, D. H., Rilling, R. A., Rogers, D. C., Stith, J. L., Albrecht, B. A., Zuidema, P., Blyth, A. M., Fairall, C. W., Brewer, W. A., Tucker, S., Lasher-Trapp, S. G., Mayol-Bracero, O. L., Vali, G., Geerts, B., Anderson, J. R., Baker, B. A., Lawson, R. P., Bandy, A. R., Thornton, D. C., Burnet, E., Brenguier, J.-L., Gomes, L., Brown, P. R. A., Chuang, P., Cotton, W. R., Gerber, H., Heikes, B. G., Hudson, J. G., Kollias, P., Krueger, S. K., Nuijens, L., O’Sullivan, D. W., Siebesma, A. P., and Twohy, C. H.: Rain in (shallow) cumulus over the ocean - the RICO campaign, B. Am. Meteor. Soc., 88, 1912-1928, 2007.

Saviv-Jovcic, V. and Stevens, B.: The structure and organization of precipitating stratocumulus, J. Atmos. Sci., 65, 1587-1605, 2008.

Seifert, A. and Beheng, K. D.: A double-moment parameterisation for simulating autoconversion, accretion and self collection, Atmos. Res., 59-60, 265-281, 2001.

Seifert, A. and Heus, T.: Large-eddy simulation of organized precipitating trade wind cumulus clouds, Atmos. Chem. Phys., 13, 5631-5645, doi:10.5194/acp-13-5631-2013, 2013.

Seifert, A., Nuijens, L., and Stevens, B.: Turbulence effects on warm-rain autoconversion in precipitating shallow convection, Q. J. Roy. Meteor. Soc., 136, 1753-1762, 2010.

Siebesma, A. P., Bretherton, C. S., Brown, A., Chlond, A., Cuxart, J., Duynkerke, P. G., Jiang, H., Khairoutdinov, M., Lewellen, D., Moeng, C.-H., Sanchez, E., Stevens, B., and Stevens, D. E.: A large eddy simulation intercomparison study of shallow cumulus convection, J. Atmos. Sci., 60, 1201-1219, 2003.

Slawinska, J., Grabowski, W. W., Pawlowska, H., and Morrison, H.: Droplet activation and mixing in large-eddy simulations of a shallow cumulus field, J. Atmos. Sci., 69, 444-462, 2012. 
Stevens, B., Cotton, W. R., Feingold, G., and Moeng, C.H.: Large-eddy simulations of strongly precipitating, shallow, stratocumulus-topped boundary layers, J. Atmos. Sci., 55, 39633984, 1998.

Stevens, B., Ackerman, A. S., Albrecht, B. A., Brown, A. R., Chlond, A., Cuxart, J., Duynkerke, P. G., Lewellen, D. C., Macvean, M. K., Neggers, R. A. J., Sánchez, E., Siebesma, A. P., and Stevens, D. E.: Simulations of trade-wind cumuli under a strong inversion, J. Atmos. Sci., 58, 1870-1891, 2001.

Stevens, B., Moeng, C.-H., Ackerman, A. S., Bretherton, C. S., Chlond, A., de Roode, S., Edwards, J., Golaz, J.-C., Jiang, H., Khairoutdinov, M., Kirkpatrick, M. P., Lewellen, D. C., Lock, A., Müller, F., Stevens, D. E., Whelan, E., and Zhu, P.: Evaluation of large-eddy simulations via observations of nocturnal marine stratocumulus, Mon. Weather Rev., 133, 1443-1462, 2005.

vanZanten, M. C. and Stevens, B.: Observations of the structure of heavily precipitating marine stratocumulus, J. Atmos. Sci., 62, 4327-4342, 2005.

vanZanten, M. C., Stevens, B., Nuijens, L., Siebesma, A. P., Ackerman, A. S., Burnet, F., Cheng, A., Couvreux, F., Jiang, H., Khairoutdinov, M., Kogan, Y., Lewellen, D. C., Mechem, D., Nakamura, K., Noda, A., Shipway, B. J., Slawinska, J., Wang, S., and Wyszogrodzki, A.: Controls on precipitation and cloudiness in simulations of trade-wind cumulus as observed during RICO, J. Adv. Model. Earth Syst., 3, M06001, doi:10.1029/2011MS000056, 2011.
Wang, L.-P. and Maxey, M. R.: Settling velocity and concentration distribution of heavy particles in homogeneous isotropic turbulence, J. Fluid Mech., 256, 27-68, 1993.

Wang, L.-P., Ayala, O., Kasprzak, S. E., and Grabowski, W. W.: Theoretical formulation of collision rate and collision efficiency of hydrodynamically-interacting cloud droplets in turbulent atmosphere, J. Atmos. Sci., 62, 2433-2450, 2005.

Wang, L.-P., Ayala, O., Rosa, B., and Grabowski, W. W.: Turbulent collision efficiency of heavy particles relevant to cloud droplets, New J. Phys., 62, 2433-2450, 2008.

Wang, Y., Fan, J., Zhang, R., Leung, L. R., and Franklin, C.: Improving bulk microphysics parameterizations in simulations of aerosol effects, J. Geophys. Res., 118, 5361-5379, 2013.

Wyszogrodzki, A. A., Grabowski, W. W., Wang, L.-P., and Ayala, O.: Turbulent collision-coalescence in maritime shallow convection, Atmos. Chem. Phys., 13, 8471-8487, doi:10.5194/acp-138471-2013, 2013.

Xue, H. and Feingold, G.: Large-eddy simulations of trade wind cumuli: Investigation of aerosol indirect effects, J. Atmos. Sci., 63, 1605-1622, 2006.

Xue, H., Feingold, G., and Stevens, B.: Aerosol effects on clouds, precipitation, and the organization of shallow cumulus convection, J. Atmos. Sci., 65, 392-406, 2008. 